\title{
Totalitarismo y democracia individualizada: un análisis de La Ola de D. Gansel
}

Por: Mag. Aleixandre B. Duche-Pérez ${ }^{1}$, Universidad Católica de Santa María, Perú; Máster Rogelio Scott-Insúa², Universidad de California, San Davis, EE.UU.; Mag. José Carlos Salinas-Valdivia ${ }^{3}$, Universidad de Washington, EE.UU. y Mag. David Blaz Sialer ${ }^{4}$, Universidad Nacional Federico Villareal, Perú

Recibido: 16 de noviembre, 2017.

Aceptado: 10 de marzo, 2018.

\section{Resumen}

El presente texto muestra que La Ola lleva a la sospecha de que el filme, más que tratar sobre el posible retorno del totalitarismo nazi en pleno siglo XXI, da una alegoría de la consolidación del imaginario democrático-liberal luego de la caída del muro de Berlín, del fin de la historia y la muerte de las ideologías.

\section{Abstract}

\section{Totalitarianism and individualized democracy: An analysis of "Die Welle" by D. Gansel}

This study shows that The Wave, rathet than addressing the return of Nazi totalitarism in the mid-21st century, it gives us an allegory of the consolidation of the liberal-democratic imaginary after the fall of the Berlin Wall, the end of history, and the death of ideologies.

1 Aleixandre Duche, es antropólogo, graduado de la Universidad Nacional San Agustín de Arequipa, Perú. En esa misma casa de estudios obtuvo su Maestría en Artes, y en la Pontificia Universidad Católica del Perú, hizo su Maestría en Antropología y cursa el doctorado en Administración Estratégica de Empresas. Es docente tiempo completo en la Universidad Católica de Santa María. Contacto: aduche@ucsm.edu.pe.

2 Rogelio Scott Insúa estudió Psicología en la Universidad Nacional de San Agustín, Perú. Además, es Máster en Antropología Médica y Global por la Universitat Rovira i Virgili, Tarragona, Cataluña, España y estudiante del doctorado en antropología y psicología médica en la Universidad de California en San Davis, Estados Unidos. Contacto: rscotti@gmail.com.

3 José Salinas Valdivia estudió Literatura en la Universidad Nacional de San Agustín, Perú. Actualmente se encuentra cursando el doctorado en Literatura en la Universidad de Washington. Contacto: jcsalinasvaldivia@gmail.com.

4 David Blaz Sialer, es antropólogo por la Universidad Nacional Federico Villarreal, Perú y Magíster en Estudios Culturales por la Pontificia Universidad Católica del Perú. Contacto: diblazsialer@hotmail.com.
Aleixandre B. Duche-Pérez, Rogelio ScottInsúa, José Carlos Salinas-Valdivia y Mag. David Blaz Sialer Totalitarismo y democracia individualizada: un análisis de La Ola de D. Gansel. Revista Comunicación. Año 39, volumen 27, número 1, enero a junio, 2018. Instituto Tecnológico de Costa Rica. ISSN: 0379-3974 / e-ISSN1659-3820.

\section{PALABRAS CLAVE:}

Totalitarismo, cine, La Ola, psicologización, perversión, posmodernidad, democracia.

\section{KEY WORDS:}

Totalitarianism, cinema, The Wave, psychologization, perversion, posmodernity, democracy. 


\section{INTRODUCCIÓN}

Una de las características actuales de películas históricas recae en que su búsqueda de realismo y coherencia parece haber encontrado en la narrativa psicológica un aliado perfecto (Hontoria y Berenguer, 2013; Gregori, 2015). Así por ejemplo, La Caída muestra los últimos días del III Reich ya no desde la épica de las trincheras y los campos de batallas, sino desde la cotidianeidad de la vida de los altos mandos nazis, sobre todo Adolf Hitler. En ella se ve a un Hitler apasionado, dividido, rabioso, un Hitler y una segunda guerra mundial reinterpretada y ambos "aclarados" desde las pasiones y personalidad de sus líderes. Este nuevo recurso está inscrito desde una época como la actual, donde la psicología y lo "psicológico" han adquirido un lugar preferencial en las producciones de ficción y las interpretaciones del pasado, respondiendo a su vez a una "demanda" de verdad psicológica por parte del público (Imhof, 2017). Es decir, lo psicológico se ha convertido en uno de los recursos principales para responder a la demanda de realismo y coherencia narrativa, inclusive causal. Vale la pena destacar que se llama psicologización al proceso por el cual las ciencias psicológicas producen la expectativa de la localización de la verdad del lado del fuero privado e íntimo de los sujetos, tanto como tecnología social, como figura narrativa.

La Ola [Die Welle] (Gansel, 2008) es una película alemana que se sirve de los recursos de la psicología y la interioridad para presentar una historia acerca del totalitarismo latente que anida en sujetos democráticos. Los medios en general han brindado buenas críticas a la película y enfatizado particularmente sus potenciales pedagógicos y cívicos. Lo que se sostendrá aquí será lo contrario. La Ola falla como texto ético al suturar el núcleo problemático de su propia textualidad. Asimismo, fracasa como texto moral al prescribir una fábula que no solo sutura, sino que además prescribe una narrativa distinta a la tensión axiológica propuesta en el mismo filme (Aertsen, 2017).

\section{MÉTODO Y ANÁLISIS}

La aproximación que se hará hacia la película no se basa en su cotejamiento con los hechos reales ni su semejanza con la realidad que erróneamente estaría obligada a re-producir. Si a pesar de esta aclaración se opta por presentar un análisis fuera de lo estético, es porque se cree que, debido a que el cine es más que una mera re-presentación de la realidad, lo es precisamente porque este constituye una interpretación de esta (Cohen, 2006). Como afirma Ubilluz (2009, p. 66), el cine (en tanto arte) y el mundo objetivo "habitan la misma esfera del lenguaje. Quiéralo o no, el arte incide -niega, cuestiona, suspende o valida- la constitución de nuestro horizonte-de-lenguaje, de nuestro mundo-objetivode-lenguaje". En otras palabras, el arte habita en el mundo del sentido y del lenguaje, y se sirve de él -de sus elementos, sus símbolos y sus mitos- para reordenarlo y presentar una creación nueva.

Si se decide realizar un análisis desde el punto de vista psicoanalítico de la cultura, es porque a pesar de no existir indicio ni garantía alguna de un sentido trascendental del texto, no obstante, este se encuentra en un universo de sentido y es capaz de anclarse en ciertas coordenadas de verdad en una época determinada. En decir, siguiendo al novelista Oz (2004), se sostiene que existen dos formas de "lectura" y de lectores: por un lado se encuentra el "mal lector", aquel que busca la última palabra del relato, que pretende encontrar en el texto las razones íntimas del autor, su biografía profunda y reducir la riqueza del texto a arquetipos equivalentes e intercambiables; en suma, aquel que presupone una verdad que se encuentra entre el autor y la obra. En contraste con el "mal lector", Oz plantea la posibilidad de uno "bueno", que busca el corazón del relato entre la obra y el lector, aquel que -parafraseando a Barthes- le pueda dar muerte al Autor.

Así, al desplazar el punto de tensión del autor al lector, la obra pasa a ser algo potencialmente distinto a una mera metáfora biográfica y simultáneamente se mantiene libre de ser reducida a una creación ahistórica. Por el contrario, pensando fenomenológicamente, la obra solo existe-en-la-lectura y el universo socio-simbólico en el que la lectura está siendo ejecutada. De esta manera, una obra nunca existe fuera del Otro, es decir, fuera de las coordenadas axiológicas y axiomáticas que le confieren un sentido. Por lo tanto, obra e interpretación son las dos facetas de un mismo proceso (Izod, 2000). Es por 
eso que se propone un análisis de la obra basado en sus propias disposiciones narrativas y textuales, pero a la vez tomando en cuenta el hecho de que ya se encuentra inscrita en una interpretación en sintonía con la época.

En ese sentido particular, ha existido un consenso tácito en los críticos y la opinión pública en general al interpretar La Ola como una historia capaz de interpelar al imaginario democrático contemporáneo (Neumann, 2013) y plantear a través de su historia una natural y ominosa contigüidad entre democracia y totalitarismo (Penarik, 2015). Este totalitarismo inminente en juego sería el "otro lado" de la democracia, el suplemento obsceno capaz de emerger a partir del malestar en ella (Arendt, 2004). No es de sorprender entonces que la película haya recibido elogios en medios tan dispares como la prensa cristiana y los portales de "contrainformación" de izquierda.

Nieto \& Aleixandre (2009) resaltan la capacidad de interpelación moral del filme, aunque también Ilegan a conclusiones diversas, inclusive opuestas: si para unos La Ola advierte de los riesgos de la debilidad moral de la juventud contemporánea (Neumann, 2013), para otros consiste en la puesta en evidencia del núcleo totalitario de la sociedad de mercado (Penarik, 2015). Lo que tienen en común todas estas interpretaciones es el reconocimiento de las grietas que la película abre en la narrativa democrática del siglo XXI y el cierre interpretativo que le confiere el estatuto de un texto moral.

\section{PONIÉNDOSE EN CONTEXTO: LA OLA [DIE WELLE] DE GANSEL}

La obra toma lugar en una escuela secundaria de la Alemania actual. La escuela programa una Semana de Proyectos orientada a "presentar a los alumnos las ventajas de la democracia", la cual consiste en unos seminarios electivos acerca de distintas formas de gobierno, entre ellas la autocracia.

Rainer Wenger, maestro de educación física y política, es parte del equipo docente que conducirá la Semana de Proyectos. Como ex-okupa y anarkopunk berlinés, Rainer se encuentra naturalmente identificado con el curso de anarquía, uno de los sistemas políticos disponibles. Desafortunadamente, otro docente toma el curso y Rainer queda derivado al curso de autocracia.

Resignado, Ileva el curso de autocracia luego de un fallido intento de negociación. Al inicio del curso se encuentra con una clase desmotivada y apática. El maestro intenta iniciar la conversación con sus alumnos: "Autocracia procede del griego y significa gobierno de uno mismo. En una autocracia el individuo o el grupo que posee el gobierno tiene tanto poder que puede cambiar las leyes como quiera [...]. ¿Alguien me puede dar un ejemplo?" (Gansel, 2008). Un alumno menciona el ejemplo del Tercer Reich. El resto de la clase reacciona con disgusto: "no quiero volver a machacar lo mismo otra vez. La Alemania nazi fue una mierda, ya me di cuenta. Aquí no puede volver a pasar algo así. No podemos sentirnos continuamente culpables con algo que no hemos hecho" (Gansel, 2008). Los alumnos expresan al unísono su disgusto ante algo que aparentemente ha quedado claro gracias a la educación políticamente sensible recibida durante toda la historia de la Alemania de post-guerra:

-Rainer, ¿no podemos hacer otra cosa? Hablemos del gobierno de Bush -dice un alumno.

-Un momento, a mí me está pareciendo interesante -responde el profesor. Piensan que en Alemania no sería posible que vuelva una dictadura, ¿cierto?

-De ningún modo -responden los alumnos-, ya hemos aprendido la lección (Gansel, 2008).

Rainer ofrece un descanso de diez minutos, que aprovecha para pensar cómo realizar una experiencia aleccionadora para sus alumnos, impermeables a los sermones habituales. Termina diseñando un experimento: en lugar de enseñar acerca de las bondades de la democracia y los peligros de la autocracia, orientará progresivamente la clase a adoptar una organización proto-fascista y exponer a los alumnos a las seducciones del totalitarismo. Establece cambios significativos en la organización de la clase. Exige que todos se dirijan a él por su apellido (Sr. Wenger) y no por su nombre 
de pila. Reorganiza la disposición de los asientos, ahora ordenados en columnas y apuntando hacia la pizarra, y ubica a los estudiantes con calificaciones bajas junto con estudiantes con notas altas, "para que puedan ayudarse". Todo aquel que quiera hablar deberá pedir la palabra y ponerse de pie. A ello Rainer acuña un eslogan: "el poder mediante la disciplina" (Gansel, 2008). Durante las siguientes clases el profesor empieza a enumerar con los alumnos las causas de una dictadura (nacionalismo, insatisfacción, desempleo, etc.).

Rainer retoma el hilo de la conversación y pregunta nuevamente sobre los requisitos indispensables para que exista un régimen autocrático; "todas las dictaduras tienen un líder" (Gansel, 2008) -le responden. La clase acuerda que el Sr. Wenger será su Führer. En las clases siguientes, además de las causas se empieza a indagar sobre las características sociales de un régimen autocrático. Conforme se van mencionando los rasgos del fascismo (uniformidad, simbología, unidad de grupo, colectivismo, anti-individualismo, etc.), la clase va progresivamente implementándolas. Finalmente, terminan formando un movimiento: La Ola.

Es importante detenerse ahí por un momento y notar que, conforme se adoptan gestos y rituales fascistas, el filme plantea que los alumnos están inequívocamente transitando de modo gradual hacia el fascismo. Esta será una asociación recurrente a lo largo de la película; a saber, "para llegar al totalitarismo no será necesaria la suscripción a ciertas ideas totalitarias, sino simplemente la adopción de la estética fascista" (Fuentes, 2014; Martin y Vioulac, 2014). Por eso el proceso culminante de la formación del movimiento de La Ola se da cuando el grupo logra elaborar con efectividad una estética compartida y diferencial (emblemas, saludos, vestimenta, que resemblarían la uniformidad fascista) respecto a las otras subculturas que habitan la escuela (punks, skaters, raperos y otros) y no mediante la suscripción a un ideario común ni por la exaltación de valores típicos del fascismo (algunos de ellos incluso sugeridos como tales al inicio de la película), como el nacionalismo extremo o el odio hacia un grupo externo. Esta última característica -es decir, el odio irracional hacia un grupo externo- resulta quizás una de las características más recordadas y emble- máticas de la Alemania nazi. Sin embargo, esa posibilidad no es planteada en ninguna parte del filme y su ausencia terminará por poner en duda si realmente La Ola fue una reactualización del fascismo y no únicamente la adopción de ciertos elementos estéticos de este. Como se verá más adelante, esta asociación se dará a lo largo de toda la trama y será uno de los puntos débiles de la película cuando la historia empiece a complicarse.

Pero entonces, ¿cómo es que alguien se convierte en un fascista posmoderno?

\section{"¡ES LA PSICOLOGÍA, ESTÚPIDO!” (O CÓMO CONVERTIRSE EN UN FASCISTA)}

Se tiene entonces un primer momento narrativo donde la semejanza entre La Ola y el fascismo se recrea por medio de la adopción de un semblante y un estereotipo: la uniformidad y la consiguiente supresión de la individualidad. Collins (2012) y Silva (2017) sostienen que esta particular interpretación del fascismo - una entre muchas otras- fue la versión oficial de la democracia liberal de post-guerra, la cual enfatizaba el papel de los individuos libres y -en cierta medida- "desidentificados" de los relatos colectivos, como requisitos indispensables para poder insertarse en el quehacer democrático.

Este tropo proviene inicialmente del liberalismo de la post-guerra (Caki, 2017), pero fue ulteriormente vuelto moneda corriente luego de la popularización de experimentos psicológicos que, inspirados en las acciones fascistas y nazis, intentaron recrear en el laboratorio situaciones donde los individuos ordinarios podrían verse envueltos en acciones que anulasen su juicio personal y maximizasen la influencia de la autoridad o la coerción grupal. Quizás el experimento más conocido de esa época fue el desarrollado por Stanley Milgram (Yukselbaba, 2017; Turowetz y Hollander, 2018). En él, un sujeto experimental común y corriente era asignado por un supervisor para ejecutar descargas eléctricas a otra persona (un cómplice del experimentador) como castigo por errores en ejercicios mentales a los que era sometido.

La idea del experimento era explorar en qué medida un sujeto era capaz de rehuir a sus propios juicios 
morales y someterse a la autoridad del científico al propinar descargas cada vez más fuertes, Ilegando incluso a shocks tan altos como de $450 \mathrm{~V}$ (evidentemente las descargas no eran reales). Lo que Stanley Milgram creyó demostrar fue una recreación experimental de la tesis arendtiana de "la banalidad del mal" en sujetos comunes y corrientes, y (aún) no cooptados por la identificación ideológica (Kaposi, 2017; Hollander y Turowetz, 2017). Si una persona ordinaria podía sucumbir tan rápidamente ante las presiones de un científico, la complicidad del pueblo alemán ante un líder carismático y una situación de crisis eran totalmente explicables científicamente. Una vez culminado el experimento, Milgram invitaba individualmente a cada participante y le exponía la naturaleza del experimento y su resultado. Luego exhortaba a su participante a realizar una reflexión moral acerca de lo sucedido.

De Vos (2009) ha elaborado un interesante análisis de los experimentos Milgram desde una perspectiva lacaniana. Según sostiene convincentemente, los momentos finales del experimento -la confesión y la reflexión autocrítica ulterior- no constituían meros detalles anecdóticos de la voluntad humanística de Milgram, sino un elemento clave del experimento y la psicología social de esa época; a saber, su labor pedagógica y su potencial como una ingeniería social efectiva. A partir de esa época se volvió más notoria y agresiva la psicologización que llevaría a cabo el Estado en todos los campos de su jurisdicción social: educación, salud, derecho, seguridad, etc., luego de que estos experimentos de consumo masivo "demostraron" la utilidad pública de la ciencia psicológica.

Si se trae esta viñeta a colación es por dos razones. La primera es por el lugar que ocupa la psicología en ambos procesos, es decir, como un agente (Milgram) y un eje narrativo central (La Ola). Esto no quiere decir - por cierto- que se pretende construir la verdad del texto por medio del "diagnóstico psicológico" de los personajes del filme (Barros, Vinicius y Dantas, 2017), sino que -por el contrariose intenta encontrar cómo la película se estructura como un caso psicológico muy similar-además de Milgram- a experimentos contemporáneos como los de Phillip Zimbardo y su "proyecto Lucifer" (Lurigio, 2009). En otras palabras, en lugar de buscar la psicología de la película, se plantea localizar la psicología en la película.

La segunda razón es para señalar los paralelos existentes entre la forma en que la psicología construye sus regímenes de verdad mediante algunos hitos significativos que sirven de alegoría a su lugar en la sociedad (Haig y Borsboom, 2012; Kaestner, 2015; Glaveanu, 2017) y la forma en que la película plantea una verdad sobre sí misma. Así, resulta evidente que el experimento Milgram y La Ola pueden ser leídos -en cierta medida- como experimentos "gemelos", sobre todo si se toma en cuenta que el caso de la vida real que inspiró la película también tomó lugar en la década de 1960 durante una clase de historia contemporánea sobre el Holocausto.

A decir verdad, la película de Dennis Cansell es una entre muchas adaptaciones artísticas de un hecho de la vida real. En 1967 un profesor de historia contemporánea de una secundaria de California decidió aplicar un experimento a sus alumnos para demostrarles, ante su estupor frente a la ignorancia (y consentimiento) que el alemán promedio ejerció durante el holocausto, cómo inclusive ellos -futuros ciudadanos de una sociedad democrática- serían capaces de sucumbir ante las seducciones totalitarias del fascismo. El experimento (denominado La Tercera Ola) consistió en la fundación de un movimiento con claras posturas totalitarias (similares a las del fascismo), tanto en la cohesión interna como en la agresividad hacia los exogrupos y sobre todo, en la supresión de los juicios individuales por sobre los colectivos. Al finalizar el experimento, se había formado un movimiento consistente y el profesor optó por revelar que La Tercera Ola era un invento y que fueron parte de un experimento para demostrar por qué los alemanes no pudieron ni quisieron denunciar el holocausto. En 1981, la cadena ABC produjo una película para la televisión. Asimismo, existen libros, documentales y hasta obras de teatro inspiradas en los hechos.

Deesta manera, la "verdad psicológica" seplantea en ambos casos como un doble pliegue. Primeramente, existe la verdad tecnológica de la psicología, es decir, aquella que se evidencia mediante la alteración fehaciente del comportamiento externo (en el caso de La Ola, la alteración total de la conducta y el 
semblante de los alumnos y, en el caso de Milgram, en la "obediencia totalitaria" de los participantes a las órdenes del científico). El segundo momento de la verdad psicológica consiste en la verdad confesional de la psicología, es decir, cuando se moviliza una comunicación reflexiva y autocrítica del estado interior de la persona acerca de su propia conducta (el ritual de confesión-reflexión en el experimento Milgram, el "malestar subjetivo" en los personajes de La Ola, además de los testimonios que elaboran una vez terminada la semana de proyectos en la escuela).

En este sentido preciso, la psicología funciona, en los términos de Lacan (1992), bajo los lineamientos del discurso universitario. En otras palabras, se trata de un discurso donde el saber (científico, tecnológico) es Amo (psicólogo) y pretende domesticar o controlar un exceso (el totalitarismo potencial en cada uno de las personas) para luego dejar como producto un sujeto "dividido" (el participante del experimento que se topa con sus propios actos monstruosos a pesar de sus valores morales).

Si La Ola y la psicología social resultan experimentos gemelos, es porque precisamente están organizados bajo coordenadas discursivas análogas y por discurso no se refiere únicamente a "una manera de decir las cosas", sino a una disposición específica de la Verdad y el Sujeto (Horne, 2007). El filme, por fines narrativos, enfatiza entonces las tensiones y separaciones entre el ámbito de lo personal y el ámbito de lo colectivo.

Al transmitir las escenas "privadas", fuera del dominio de la escuela, la película enfatiza en exponer a los alumnos como conducidos por una vida de "excesos" (fiestas, alcohol, drogas, etc.), pero también con carencias y falta de sustancia (soledad, frustración, crisis de identidad). Este planteamiento se constituye en la narración como el caldo de cultivo perfecto desde donde podría anidar una seducción y una satisfacción con el fascismo (Fabbri, 2015).

Si bien la figura de la personalidad débil es una muletilla muy común tanto en el cine como en la psicología pop, no obstante es quizás en las películas actuales sobre nazis donde se ha explotado mejor esta tensión. Por ejemplo, en Der Untergang
[La Caída], se muestra a un Hitler frustrado, dividido e impotente durante los últimos años del III Reich. Igualmente, en Inglourious Basterds [Bastardos sin gloria], Quentin Tarantino retrata a unos nazis acomplejados e inseguros. En La Ola, el vacío de la vida íntima será lo que sintonizará con las seducciones del fascismo.

En ese sentido, si -según los propios diálogos al comienzo de la película- los alumnos inicialmente planteaban que la autocracia era producto de la crisis social y económica, en la pandilla de La Ola -por el contrario- su "fascismo" era producto de una crisis personal y hasta cierto punto, una crisis de adolescencia. No se está sugiriendo que el filme proponga reinterpretar los hechos de la historia en clichés psicológicos vulgares ("los nazis tenían complejos de inferioridad frente a los judíos", "Hitler tuvo problemas en la infancia"), sino cómo ignora la crítica al malestar en la democracia y el goce contemporáneos que la película misma había elaborado (un malestar con la misma democracia que los alumnos debían valorar) y lo sustituye argumentativamente por una progresiva sincronización entre el fuero privado y el ámbito público (Eder, 2006; Gibbs, 2017). Es así que, por ejemplo, al final de la historia, Tim termina organizando un pequeño tiroteo que culmina en su suicidio, haciendo notar que su acto fue un hecho de locura latente generada por su soledad e incomprensión, pero activada por el totalitarismo de La Ola. De esta manera, todos los personajes principales, incluido el profesor Rainer, ven La Ola como el medio para y el producto del desahogo de las frustraciones individuales y privadas.

En este punto se llega a un atolladero: ¿Si La Ola se erige en la crítica como un texto moral y una fábula, entonces cómo es que explica el fenómeno totalitario? Es decir, ¿si La Ola es un texto moral, cómo plantea su moraleja?

\section{LA DEMOCRACIA INDIVIDUALIZADA (O "LO SOCIAL ES MALO PARA TI")}

En el apartado anterior se dijo que el filme expone su propia interpretación en las transiciones narrativas que van del fuero individual y privado (presuntamente) "democrático" al ámbito público 
y colectivo (presuntamente) "totalitario". En esta sección se explorará con mayor detalle este tránsito para luego intentar recortar y elaborar, como sostiene Gaut (2010), el cierre moral que se plantea al final de la historia e interpela por igual a críticos conservadores y progresistas.

El punto de partida son entonces las figuras del exceso y el vacío existencial. En una de las primeras escenas, los jóvenes de la escuela están bebiendo y bailando desenfrenadamente en una fiesta. En ella Marco discute con su amigo Martin:

-Martin, dime una cosa, ¿contra qué debe una persona rebelarse hoy en día? De todos modos ya nada tiene sentido. La gente ahora sólo piensa en su propio placer. Lo que le falta a nuestra generación es una meta conjunta que nos una.

-Son los tiempos que vivimos. Mira a tu alrededor, ¿quién es la persona más buscada en internet? La maldita Paris Hilton... (Gansel, 2008).

Obviamente este diálogo catapulta el anhelo por una causa común y colectiva, ya que los motivos para rebelarse se han agotado. Unión y rebelión son asociados entonces como intercambiables (Herrero, 2016). Pero además, se tiene en la misma escena el contraste entre el desenfreno anómico y "atomizado" de los jóvenes y a Marco interrogándose por su generación. Por lo tanto que los miembros de su generación no estén unidos no implica únicamente que carezcan de utopías o grandes narrativas, sino que fundamentalmente se encuentran solos. $Y$ es esta soledad la que precisamente interpela a la misma narrativa democrática presente en el texto fílmico.

Si la democracia se encuentra fundamentalmente anidada en el fuero privado (ya que como se observa en el filme, el peligro totalitario proviene del ámbito colectivo y público) y si esa pax democrática privada solo se puede mantener con individuos aislados (Fay, 2018), esto quiere decir que la democracia falló en su proyecto de crear un mejor lazo social entre los hombres, por el sencillo hecho de haberse diluido el lazo social sustancial entre ellos. En otras palabras, si se lleva hasta el final la inter- pretación que desde esta escena se hace de todo el filme, la conclusión a la que se llega es que si en la Alemania actual (de la película) aún no se ha "regresado" a la autocracia no es por la presencia de un lazo social cualitativamente superior, sino por la virtual desaparición de vínculos sociales (Kapczynski, 2015; Rulinskiy, 2016). Es de este modo que la misma pregunta de Marco puede ser el hilo conductor de la trama de la película en todos los ámbitos en que se consolida y se exponen los vínculos de La Ola.

En otra secuencia, se ve al equipo de waterpolo (que el mismo Rainer entrena) incapaz de conseguir una victoria a causa del individualismo de cada uno de sus competidores. Luego de la primera sesión del experimento, Marco y Sinan -otrora rivales en su mismo equipo- acuerdan pasarse el balón para anotar un gol durante un entrenamiento y lo consiguen. Es entonces cuando los jóvenes empiezan a apreciar los beneficios del "poder mediante la disciplina" (Wolf, 2018), aprendido gracias a Rainer y La Ola, y cuando sus vidas empiezan a cambiar. Los antiguos enemigos comienzan a amistarse y trabajar juntos (es destacable la escena donde Marco y Sinan, antiguos oponentes, festejan juntos antes de un partido decisivo de waterpolo contra una escuela rival), quienes antes eran solitarios inician a formar lazos de amistad y protección (como la escena en que el ermitaño Tim es defendido por sus nuevos amigos en una discusión con unos punks) y los egoístas empiezan a ceder para actuar solidariamente.

Es en este punto en que el andamiaje del filme se tambalea, ya que es precisamente la idea sostenida a lo largo de la historia que la aprehensión del fascismo se da por medio de la adopción de la estética fascista (Borkovetz, 2004; Spackman, 2006), sobre todo lo que está relacionado con lo colectivista y lo uniforme) que al final de la película no queda claro si La Ola terminó siendo un grupo fascista stricto sensu o simplemente un grupo subcultural, algo agresivo, pero con todas las características de una subcultura.

Una de las escenas más ambiguas de la película es cuando Rainer -consciente de que La Ola se le fue de las manos- convoca a todos los simpatizantes al 
auditorio con la intención de disolverla y develar a los alumnos en qué se habían convertido. Entonces el maestro empieza a leer los testimonios anónimos de La Ola...

-"Siempre he tenido todo lo que quería: ropa, dinero, etc., pero lo que siempre tenía era aburrimiento, pero estos últimos días han sido muy entretenidos...".

-"Ya no se trata de quién es la más bonita, la mejor o la de más éxito. La Ola nos ha hecho a todos iguales...".

-“La procedencia, la religión y el entorno social ya no tienen ninguna importancia. Todos pertenecemos a un movimiento...".

-"La Ola nos da un nuevo significado, ideales que merece la pena apoyar...".

-"Antes solía golpear a otros, cuando pienso sinceramente sobre ello me parece algo bastante anarquista, es mucho mejor comprometerse con algo...".

-"Si uno puede confiar en los demás conseguiremos más cosas, por eso estoy dispuesto a sacrificarme..." (Gansel, 2008).

Si se presta atención a los testimonios, resulta difícil encontrar un rasgo eminentemente totalitario o fascista. Por el contrario, lo que los testimonios movilizan es una satisfacción inédita con el lazo social y una excursión por las situaciones tensas que cada testimoniante contrasta con su pasado. Es por esto que resulta irónico que en el preciso momento en que Rainer sancionaría a La Ola por su clara vocación autoritaria y segregacionista, se encuentran alumnos testimoniando tener por primera vez "ideales" y deseos de "comprometerse con algo" -en lugar de estar golpeando a los demás-, gente dispuesta a "confiar en los demás" y alumnos para quienes las diferencias culturales y económicas "ya no tienen ninguna importancia". En suma, más que un movimiento fascista, se evidencia -como sostiene Klevan (2014)- un campo mayor donde el lazo social forma una comunidad. Y si este es el momento culminante en que se muestra "la captura ideológica" de los alumnos a partir de la confesión íntima de sus sentimientos, la pregunta por hacerse debería ser: ¿es esto realmente fascismo? Queda demostrado que esta escena es una interpelación a la sanción moral del espectador. No obstante, hay que preguntarse si lo que se sanciona es necesariamente el totalitarismo o el lazo social en sí.

Si esta confusión entre comunidad (lazo social) y fascismo complica inmediatamente la narración, el asunto empeora cuando se ve que La Ola -en su momento de esplendor- logra cohesionarse tranquilamente sin la necesidad de haber elaborado un grupo-objeto externo de odio (como los judíos para los nazis) ni de un ideario o una ideología. Haciendo una clara alegoría a un discurso hitleriano, Rainer empieza a agitar a las masas en medio de aplausos fervorosos. El maestro muestra el totalitarismo de La Ola en todo su exceso cuando pretende llevar hasta el final el éxtasis de la audiencia y en un exacto juego con el fantasma del público, encarna la grieta misma que La Ola abrió en el status quo:

-Estoy muy impresionado de lo que La Ola les ha aportado. Y por eso creo que este proyecto no debe terminar aquí. [...] Desde hace años Alemania va cuesta abajo. Somos los perdedores de la globalización. Los políticos nos quieren hacer creer que para salir de la crisis hay que rendir más. Pero los políticos son solo marionetas de la economía: "la cuota de desempleo está bajando, somos el primer país en exportaciones". Pero la realidad es que los pobres son cada vez más pobres y los ricos más ricos. La única gran amenaza es el terror. Un terror que nosotros mismos hemos creado, mediante la injusticia que permitimos en el mundo. $\mathrm{Y}$ mientras que nosotros poco a poco, pero sin descanso destruimos el planeta, unos cuantos supermillonarios se sientan por ahí y se frotan las manos, se construyen naves espaciales y observan lo que ocurre incluso desde el espacio.

- ¿Es que no se dan cuenta de lo que pretende? ¡Los está manipulando! -interviene un desengañado Marco. 
-No me vas a impedir que diga la verdad, Marco.

- ¡La Ola es el verdadero problema!

-No, La Ola es la única vía para arreglar el camino que están tomando las cosas. Juntos podemos conseguirlo todo. Nosotros hoy tenemos aquí la posibilidad de hacer historia (Gansel, 2008).

Si el lector encuentra increíblemente confuso el discurso de Rainer, es porque abre la posibilidad de un cambio radical luego de exponer el agujero inherente en la democracia neoliberal de la Alemania actual que la Semana de Proyectos debía enaltecer ("los ricos se hacen cada vez más ricos y los pobres más pobres", "hemos creado un terror nosotros mismos", "estamos destruyendo el planeta") (Birgel, 2009; Bilis, 2017). Solo aislando este fragmento se puede apreciar el proceso de sutura ideológica en el que se envuelve la textualidad de la película, ya que -antes que nada- la ambigüedad del sujeto enunciador (no se puede ver claramente si está parodiando un discurso izquierdista alter-globalizador y equiparándolo con el totalitarismo o si está siendo fiel a la grieta abierta en el discurso de la democracia formal expuesta por la experiencia de La Ola) no anticipa el sentido que el resto de la historia tomaría.

En resumen, al escuchar a Rainer pronunciar un discurso que tranquilamente hubiera sido importado de sus años mozos, cuando vivía en una casa okupa berlinesa luchando contra la policía y en solidaridad con algún país del tercer mundo, ahora se encuentra narrativamente teñido de "fascismo". No se puede encontrar un mejor ejemplo de lo que significa en el fin de la historia y la caída de los grandes ideales.

Más que un filme sobre la Alemania nazi, se ve cada vez más que el filme alegoriza la caída del muro de Berlín y las consecuencias civilizatorias que acarreó tal acontecimiento (O'Brien, 2009; Tapper, 2013) al parodiar Rainer un discurso con inmediatas resonancias con una agitación socialista y simultáneamente al descalificarlo al plantearlo como análogo a un caduco discurso nazi (Von Moltke, 2007).
Unos minutos más adelante, se evidencia que efectivamente Rainer se aleja del agujero abierto en el Otro de la democracia, solo para coger vuelo y romper radicalmente con La Ola:

- ¿No se han dado cuenta de lo que ha pasado aquí? [...] ¿No se acuerdan ya de la pregunta que surgió al inicio de la clase: si una dictadura era posible en estos tiempos? Pues es lo que acabamos de ver, fascismo. Todos nos hemos considerado mejores, mejores que los demás. Y lo que es aún peor, hemos excluido de nuestro grupo a todos aquellos que no pensaban igual. Les hemos hecho daño y no quiero pensar de qué más habríamos sido capaces. Les tengo que pedir disculpas. Hemos ido demasiado lejos, yo he ido demasiado lejos. Todo esto se acabó.

- ¿Y qué significa eso para La Ola?

- Que se ha terminado.

- Pero no todo estaba mal en La Ola. Todos lo hemos sentido, hemos cometido errores, pero podemos corregirlo.

- No, Dennis, algo así no se puede corregir. Quiero que todos vayan a casa ahora. Creo que tienen muchas cosas sobre las que reflexionar (Gansel, 2008).

Efectivamente, como dice Rainer, habían ido demasiado lejos, pero no en la dirección aparente. Fueron "demasiado lejos" al no quedarse con el civismo celebratorio de la democracia globalizada que se les asignó como proyecto pedagógico (Bluestone, 2000; Oh, De Gagné y Kang, 2013). Fueron demasiado lejos al procesar el malestar que la sociedad de consumo y la competitividad meritocrática que esta les planteaba. Fueron lejos al transgredir los muros tácitos que convierten a los inmigrantes en ciudadanos de segunda clase dentro de la sociedad europea. Y frente a ese exceso, Rainer retrocede, diciendo además que La Ola en su conjunto es un error insalvable.

Parafraseando a De Vos (2009), Rainer se coloca a sí mismo en una posición meta-humana y asume 
la tarea de ser un mero sirviente de la democracia para -paradójicamente- humillar a sus alumnos. Según el psicoanálisis, la reducción de uno mismo al estatuto de un instrumento del Otro (la ciencia, la democracia, el partido) es estrictamente homóloga a la posición del perverso. Como sostiene Lacan (2007), el perverso ocupa el lugar del objeto para el beneficio de otro, para quien goza sádicamente. Es como si Rainer estuviera diciendo tácitamente: "no es mi deseo ni mi responsabilidad el traer toda esta monstruosidad fascista a la luz, yo sólo soy un instrumento de la democracia" (Gansel, 2008).

El experimento de La Ola, desde el inicio, estuvo programado para llegar al momento del desengaño, del levantamiento del velo para revelar la desnudez de la -supuestamente- verdadera naturaleza (totalitaria) de los alumnos. Para ponerlo en términos sencillos, la lección que brinda el experimento de Rainer es el poder de este, así como la "la cátedra psicológica que nos da [el experimento Milgram] es acerca del poder de la psicología" (De Vos, 2009, p. 237).

El filme culmina mucho antes de la aparición de los créditos finales. Solo se mencionará que luego de la sanción perversa de Rainer, Tim -el alumno más entusiasta para con La Ola- termina suicidándose.

\section{CONCLUSIÓN: “GOODBYE, HITLER”}

Como ya se expuso, un análisis más detallado de La Ola lleva a la sospecha de que el filme, más que tratar sobre el posible retorno del totalitarismo nazi en pleno siglo XXI, hace una alegoría de la consolidación del imaginario democrático-liberal luego de la caída del muro de Berlín, del fin de la historia y la muerte de las ideologías (Hochscherf y Winkel, 2016). El mensaje es medianamente claro: el fascismo estuvo muerto desde la capitulación de 1945. Lo que actualmente peligra es el modelo universal de la democracia neoliberal, que empieza a presentar sus agujeros en la película y en la realidad.

Es importante notar que incluso en los últimos años el pensamiento de extrema derecha en la Europa nórdica ha asimilado un nuevo semblante totalmente alejado del fanatismo étnico y antisemita de antaño. Recuérdese, por ejemplo, a Pim Fortuyn, el candidato holandés de extrema derecha. El clivaje que activaba ya no era un conservadurismo racial y sexual, sino un "choque de civilizaciones" en los que se encomendaba como el defensor de las conquistas civiles y liberales de los países occidentales, incluyendo el hecho de que un gay como él puede darse el lujo de postularse a la presidencia de su país, a diferencia de países teocráticos de Medio Oriente. Se Puede ver que luego de la caída del muro y el antagonismo capitalismo/comunismo, el paradigma del "choque de civilizaciones" ha pasado a convertirse en el framing por antonomasia para pensar las contradicciones del mundo luego del 11 de setiembre de 2001 (Stefanoni 2011).

En su ya repetitiva comparación entre los dos totalitarismos del siglo XX, el fascismo y el stalinismo, Slavoj Zizek -no obstante- deja en claro que ambos son radicalmente distintos. Los aspectos políticos del pasado comunista están borrados y actualmente en los ex-países eurocomunistas se ha erigido una nostalgia vintage acerca de los aspectos idílicos de la vida cotidiana bajo el totalitarismo del partido comunista. Es decir, si bien tanto el nazismo como el stalinismo están prohibidos en la narrativa neoliberal, no lo están de la misma manera: "Aún cuando tenemos plena conciencia de sus aspectos monstruosos, Ostalgie nos parece aceptable" (Zizek, 2004, p. 201). Y como continúa el chiste, Good bye, Lenin nos parece aceptable, pero no Goodbye, Hitler.

¿Dónde se posiciona entonces La Ola? ¿No es la película una versión inversa a la nostalgia vintage, un Goodbye, Hitler? No necesariamente. Si Good bye, Lenin funcionaba como un manifiesto nostálgico de la ingenuidad comunista y el grito de victoria del sistema mundial post-guerra fría (Laucht, 2008), La Ola termina operando como una sutura ante las contradicciones del mundo post-11 de setiembre y la crisis del sistema financiero internacional, es decir, los años posteriores al quebrantamiento del sueño del mundo unipolar. ¿Y la psicología? ¿Si el experimento Milgram pretendió responder perversamente a la "banalidad del mal", creando un Auschwitz psicológico y experimental (De Vos, 2011), no será acaso el experimento de la prisión de Standford una réplica en laboratorio de Abu Ghraib en la era de la guerra contra el terror? 


\section{BIBLIOGRAFÍA}

Aertsen, V. (2017). Sympathy for fictional characters: an examination of the factors involved from a social psychology and cognitive film theory perspective. Doxa Comunicación, 25, 107-128.

Arendt, H. (2004). Los orígenes del totalitarismo. Madrid: Taurus.

Barros, M., Vinicius, M. y Dantas, V. (2017). GestaltTherapy: the question of the subject psychotic in the film "Tideland". Ecos-Estudos Contemporaneos Da Subjetividade, 7(2), 340-348.

Bilis, P. (2017). The cinema of Germany: a historical evaluation of the erratic course of a national film industry. Istanbul Universitesi Iletisim Fakultesi Dergisi, 52, 89-108.

Birgel, F. (2009). Kuhle Wampe, Leftist Cinema, and the Politics of Film Censorship in Weimar Germany. Historical Reflections-Reflexions Historiques, 35(2), 40-62.

Bluestone, C. (2000). Feature films as a teaching tool. Coll Teach., 48, 141-146.

Borkovetz, R. (2004). Did fascist aesthetics win the war? (The National World War II Memorial). Landscape Architecture, 94(9), 14-+.

Caki, C. (2017). Nazism ideology in Turkish cinema: "Kirimli" film and semiotics analysis. Istanbul Journal of Sociological Studies-Sosyoloji Konferanslari, 56, 65-93.

Cohen, J. (2006). Audience identification with media characters. Psychology of Entertainment, 183-197.

Collins, J. (2012). The advent of democracy, vol 3, the test of totalitarism, 1914-1974. New Left Review, 74, 145-154.

De Vos, J. (2009). Now That You Know, How Do You Feel? The Milgram Experiment and Psychologization. Annual Review of Critical Psychology, 7, 223-246.

De Vos, J. (2011). From Milgram to Zimbardo: The Double Bith of Post-War Psychology/Psycholo- gization. History of the Human Sciences, 23(5), 156-175.

Eder, J. (2006). Ways of Being Close to Characters. Film Studies, 8, 68-80.

Fabbri, L. (2015). Neorealism as ideology: Bazin, Deleuze, and the avoidance of fascism. Italianist, 35(2), 182-201.

Fay, J. (2018). Democratic Film and the Aesthetics of Choice. German Life and Letters, 71(2), 169192.

Fuentes, F. (2014). Totalitarism a glance from the 21 st century. Revista de Occidente, 400, 5-6.

Gaut, B. (2010). Empathy and Identification in Cinema. Film and the Emotions, 34, 136-157.

Gibbs, A. (2017). 'What Makes My Image of Him into an Image of Him?': Philosophers on Film and the Question of Educational Meaning. Journal of Philosophy of Education, 51(1), 267-280.

Glaveanu, V. (2017). Psychology in the Post-Truth Era. Europes Journal of Psychology, 13(3), 375377.

Haig, B. \& Borsboom, D. (2012). Truth, science, and psychology. Theory \& Psychology, 22(3), 272289.

Herrero, M. (2016). Religion and the Political: The Answer of Hegel's Philosophy between Tension and Reconciliation. Pensamiento, 72(271), 279294.

Hochscherf, T. y Winkel, R. (2016). Third Reich Cinema and Film Theory. Historical Journal of Film Radio and Television, 36(2), 190-213.

Hollander, M. y Turowetz, J. (2017). Normalizing trust: Participants' immediately post-hoc explanations of behaviour in Milgram's "obedience' experiments. British Journal of Social Psychology, 56(4), 655-674.

Horne, M. (2007). There is no 'truth' outside a context: implications for the teaching of analytical psychology in the 21(st) century. Journal of Analytical Psychology, 52(2), 127-142. 
Imhof, R. (2017). Characters on the Couch: Exploring Psychology through Literature and Film. Reference \& User Services Quarterly, 56(3), 215-215.

Izod, J. (2000). Active imagination and the analysis of film. J Analytical Psychol., 45, 267-85.

Kaestner, L. (2015). Epistemic Cognition and Development: The Psychology of Justification and Truth. International Studies in The Philosophy of Science, 29(4), 444-447.

Kapczynski, J. (2015). Screen Nazis: Cinema, History and Democracy. Screen, 56(2), 289-293.

Kaposi, D. (2017). The resistance experiments: Morality, authority and obedience in Stanley Milgram's account. Journal for the Theory of Social Behaviour, 47(4), 382-401.

Klevan, A. (2014). Vertigo and the Spectator of Film Analysis. Film-Philosophy, 18, 147-171.

Lacan, J. (2007). Seminario X. La angustia. Buenos Aires: Paidós.

Lacan, J. (1992). Seminario XVII. El reverso del psicoanálisis. Buenos Aires: Paidós.

Laucht, C. (2008). Film propaganda in Britain and Nazi Germany: World War II cinema. Historical Journal of Film Radio and Television, 28(1), 8082.

Lurigio, A. (2009). The Rotten Barrel Spoils the Apples: How Situational Factors Contribute to Detention Officer Abuse Toward Inmates A Review of The Lucifer Effect, by Philip Zimbardo. Prison Journal, 89(1), 70S-80S.

Martin, E. \& Vioulac, J. (2014). Totalitarism without a state. Liberte, 303, 11-17.

Neumann, J. (2013). Die Auseinandersetzung mit Auschwitz durch das Medium Film im Religionsunterricht. Eine Filmanalyse zu «Die Welle». Berlin: Grin.

Nieto, M. \& Aleixandre, V. (2009). LA OLA. Manipulación y control a través de la imagen. Red Visual. Miradas sobre cine, 11.
O'Brien, M. (2009). Nazi Cinema as Enchantment: The Politics of Entertainment in the Third Reich. Forum for Modern Language Studies, 45(2), 228-229.

Oh, J., De Gagné, J. y Kang, J. (2013). A review of teaching-learning strategies to be used with film for prelicensure students. J Nurs Educ. 52, $150-6$.

Oz, A. (2004). Una historia de amor y oscuridad. Madrid: Silueta.

Penarik, N. (2015). Analyse der didaktischen werte in dem film "die welle" Von Dennis Gansel (Tesis de doctorado). Universitas Negeri Medan, Medan, Indonesia.

Rulinskiy, V. (2016). Overcoming Nazi past in Germany at the present stage. Goldhagen phenomenon. Contemporary Europe-Sovremennaya Evropa, 5, 67-78.

Silva, E. (2017). Hannah Arendt and Agamben: totalitarism as a biopolitic category and the politization of life in liberal democratic societies. Kalagatos, 14(2), 271-287.

Spackman, B. (2006). The unmaking of fascist aesthetics. Political Communication, 23(3), 355358 .

Stefanoni, P. (2011). Extremas derechas. ¿Del racismo al culturalismo? Página 7.

Tapper, M. (2013). Nazisploitation! The Nazi Image in Low-Brow Cinema and Culture. Historical Journal of Film Radio and Television, 33(1), 176178.

Turowetz, J. y Hollander, M. (2018). From "Ridiculous" to "Glad to Have Helped": Debriefing News Delivery and Improved Reactions to Science in Milgram's "Obedience" Experiments. Social Psychology Quarterly, 81(1), 71-93.

Ubilluz, J. (2009). El fantasma de la nación cercada. En: J. Ubilluz, V. Vich y A. Hibbett (Eds.), Contra el sueño de los justos: La literatura peruana ante la violencia política (pp. 19-85). Lima: IEP. 
Von Moltke, J. (2007). Nazi cinema revsited. Film Quarterly, 61(1), 68-72.

Wolf, K. (2018). Power struggles: A sociological approach to activist communication. Public Relations Review, 44(2), 308-316.

Yukselbaba, U. (2017). Milgram experiment about authority and obedience. Journal Of Istanbul University Law Faculty-Hukuk Fakultesi Mecmuasi, 75(1), 227-270.

Zizek, S. (2004). La suspensión política de la ética. México DF: Fondo de Cultura Económica.

\section{FILMOGRAFÍA}

Gansel, D. (2008). Die Welle [La Ola]. Berlín: Rat Pack Filmproduktion. 